\title{
Effect of L-Arginine on Collagen of High Flow-Induced Pulmonary Arterial Remodeling
}

\author{
Du Junbao, MD; Yan Hui, MD; Wei Bing, MD; Li Jian, MD*; \\ Qi Jianguang, $\mathrm{PhD}$; Tang Chaoshu, $\mathrm{PhD}^{* *}$
}

\begin{abstract}
Background Pulmonary hypertension $(\mathrm{PH})$ is a common complication of congenital heart disease and pulmonary vascular structural remodeling due to the high pulmonary blood flow is considered as the key pathologic process. In the present study the effects of L-arginine on the collagen metabolism of pulmonary arteries in rats with high pulmonary blood flow-induced PH were investigated to elucidate its mechanism.

Methods and Results The rat model of PH was established with an abdominal aorta and inferior vena cava shunt. L-arginine ( $1 \mathrm{~g} / \mathrm{kg}$ per day) was given directly into the stomachs of the rats with the shunt (L-arginine+ shunt group) and 11 weeks later, the pulmonary hemodynamics were studied. Collagen I and collagen III expressions were detected by immunohistochemical assay. The expressions of procollagen I mRNA, procollagen III mRNA, the tissue inhibitor of metalloproteinase-1 mRNA and the matrix metalloproteinase-1 mRNA were detected by in situ hybridization. The expressions of pulmonary artery collagen I, collagen III, procollagen I mRNA and procollagen III mRNA in the shunt rats were obviously elevated compared with the control rats $(\mathrm{p}<0.01)$. The positive signals were mainly located in the media and adventitia of median and small pulmonary arteries. The expressions of the pulmonary artery tissue inhibitor of metalloproteinase- 1 mRNA, metalloproteinase- 1 mRNA and the ratio of tissue inhibitor of metalloproteinase-1/metalloproteinase- 1 were elevated in the shunt rats $(\mathrm{p}<0.01)$. However, the expressions of pulmonary artery collagen I, collagen III, procollagen I mRNA and procollagen III mRNA were significantly reduced in the shunt rats of the L-arginine group ( $\mathrm{p}<0.01)$. L-arginine also downregulated the expressions of tissue inhibitor of metalloproteinase-1 mRNA and metalloproteinase-1 mRNA, as well as the ratio of tissue inhibitor of metalloproteinase-1/metalloproteinase-1 $(\mathrm{p}<0.05)$.

Conclusions L-arginine can reduce the synthesis of extracellular matrix-collagen and increase its degradation, thus having an important modulating effect on pulmonary vascular matrix remodeling induced by high pulmonary blood flow. (Circ J 2005; 69: 603-608)
\end{abstract}

Key Words: Collagen; L-arginine; Pulmonary hypertension

$\mathbf{P}$ ulmonary hypertension $(\mathrm{PH})$ is a common complication of congenital heart disease and pulmonary vascular structural remodeling because of the high pulmonary blood flow is considered as the key pathologic basis. The accumulation of extracellular matrix collagen, the main component of pulmonary vascular matrix remodeling, is an important process of pulmonary vascular structural remodeling!-5 Previous studies indicated that L-arginine/nitric oxide could alleviate the development of high pulmonary blood flow-induced pulmonary vascular structural remodeling and high pulmonary blood flow-induced $\mathrm{PH}$, but the mechanism remains unclear:-8

In the present study, we investigated the impact of L-arginine on collagen content and the effect of L-arginine on the main molecules modulating the synthesis and degradation of collagen in the pulmonary arteries of rats with high pulmonary flow in order to explore the possible mechanism by

(Received November 5, 2004; revised manuscript received January 27, 2005; accepted February 21, 2005)

Departments of Pediatrics, *Thoracic Surgery, and **Institute of Cardiovascular Research, First Hospital, Peking University, and Key Laboratory of Molecular Cardiovascular Sciences, Ministry of Education, Beijing, China

Mailing address: Du Junbao, MD, Department of Pediatrics, Peking University First Hospital, Xi-An Men Street No. 1, Beijing 100034, PR China._E-mail: junbaodu@ht.rol.cn.net \& yanhuisummer@hotmail. com (please use both e-mail addresses to contact us) which L-arginine regulates pulmonary matrix remodeling.

\section{Methods}

\section{Animal Model Preparation}

Male Sprague-Dawley rats $(n=21)$ were randomly divided into a control group $(n=7)$, shunt group $(n=7)$ and shunt with L-arginine group $(n=7)$. The studies met the National Research Council's Guide for the care and use of laboratory animals.

In the shunt group and shunt $+\mathrm{L}$-arginine group, rats were anesthetized using $0.25 \%$ pentobarbital sodium $(40 \mathrm{mg} / \mathrm{kg})$ for creation of an abdominal aorta-inferior vena caval shunt. The abdominal aorta and inferior vena cava were exposed by opening the abdominal cavity via a midline incision. A bulldog vascular clamp was placed across the aorta caudal to the left renal artery and the aorta was punctured with a 12 gauge disposable needle at the union of the segment two-thirds caudal to the renal artery and one-third cephalic to the aortic bifurcation. The needle was advanced into the aorta at a $45^{\circ}$ angle, perforating the adjacent wall and penetrating the vena cava. Then the needle was slowly withdrawn and a 9-0 silk thread was used to suture the incision. The clamp was removed $30 \mathrm{~s}$ later and the patency of the shunt was verified visually by the swelling of the vena cava and the mixing of arterial and venous blood. The peritoneal cavity was closed with silk sutures and gentamycin 
was injected for the prevention of infection. Control rats underwent the same procedure except for the creation of the shunt.

For rats in the shunt $+\mathrm{L}$-arginine group, $\mathrm{L}$-arginine was orally administrated at a dose of $1 \mathrm{~g} / \mathrm{kg}$ daily from the second day onward after operation. An equal volume of normal saline was given to the rats in the control group and shunt group. Housing and husbandry conditions were the same for each group of rats.

\section{Measurement of Pulmonary Artery Pressure}

Eleven weeks after the experiment, the animals were weighed and anaesthetized with pentobarbital sodium $(40 \mathrm{mg} / \mathrm{kg})$. The mean pulmonary artery pressure of each rat was evaluated by a right cardiac catheterization procedure. A polyethylene catheter was inserted into the external jugular vein and advanced under fluoroscopic guidance to a branch of the main pulmonary artery. The other end of the catheter was connected to a transducer and the pressure tracings were simultaneously recorded on a physiologic recorder (90308-11-17-38, SpaceLabs, USA).

\section{Blood Gas Analysis and Measurement of QP/QS}

Blood samples $(2 \mathrm{ml})$ were obtained from the pulmonary artery, external carotid artery and jugular vein for blood gas analysis using a GASTAT-3 Blood Gas Analysis Apparatus. $\mathrm{QP} / \mathrm{QS}$ was calculated by the formula: $\mathrm{QP} / \mathrm{QS}=$ [oxygen saturation of aorta $(\%)$-oxygen saturation of inferior vena cava $(\%)] /[$ oxygen saturation of pulmonary vein $(\%)$ oxygen saturation of pulmonary artery $(\%)]$.

When the oxygen saturation of the aorta was $>95 \%$, the oxygen saturation of the pulmonary vein was regarded as $100 \%$. When the oxygen saturation of aorta was $<95 \%$, the oxygen saturation of the pulmonary vein was regarded as $95 \%$.

\section{Preparation of Lung Tissue}

One lobe from both lungs was excised, fixed in $10 \%$ formalin and routinely processed into paraffin sections of $4-5 \mu \mathrm{m}$ in depth. Sections were used for immunohistochemistry and in situ hybridization.

\section{Immunohistochemical Analysis}

After dewaxing with dimethylbenzene, the sections of lung tissues were put into distilled water and then blocked in $\mathrm{H}_{2} \mathrm{O}_{2}$ for 20 min. The slides were washed twice, each for $5 \mathrm{~min}$ and then the antigens were heat-processed $\left(92-98^{\circ} \mathrm{C}\right)$ for $15 \mathrm{~min}$. The slides were rinsed twice in phosphate-buffered saline, each for $5 \mathrm{~min}$, and then blocked for $10 \mathrm{~min}$ with sheep (goat) serum working fluid. Collagen I and collagen III antibodies diluted 1:100 (Santa Cruz) were added and incubated at $4{ }^{\circ} \mathrm{C}$ overnight, after which the slides were rinsed in phosphate-buffered saline twice, for $5 \mathrm{~min}$ each. Next, biotinylated 2 nd antibody was added for $30 \mathrm{~min}$ at $37^{\circ} \mathrm{C}$. The sections were incubated with avidin-biotin complex at $37^{\circ} \mathrm{C}$ for $30 \mathrm{~min}$. Then DAB was added for developing color and the sections were stained with hematoxylin. After the sections were dehydrated through a graded ethanol series and cleared in dimethylbenzene the slides were mounted. Brown granules in pulmonary smooth muscle cells under the microscope were defined as positive signals.

The collagen expression by pulmonary artery smooth muscle cells was examined using a semi-quantitative method. We defined it as negative (-) if there was no positive signal in the cells. If $1-50 \%$ of smooth muscle cells in the pulmonary artery showed collagen expression, we defined it as (+). If $51-100 \%$ of smooth muscle cells showed collagen expression, it was defined as $(++)$. At least 10 medium and small pulmonary arteries were examined for each slide. For the convenience of understanding and statistical process, the content of collagen protein in the pulmonary arteries was expressed in integration as calculated: the percentage of pulmonary arteries with a certain extent of reaction intensity was multiplied by the weighted values of their reaction intensity. The weighted value of reaction intensity was $0,0.5$ and 1.0 if the reaction intensity was -, ,+++ , respectively.

\section{In Situ Hybridization}

Plasmid DNA was extracted by bacterial conversion and alkali pyrolysis method, then incised with restriction endonuclease. We retrieved corresponding fragments and labeled them with digoxigenin (DIG). DIG-labeled tissue inhibitor of metalloproteinase-1 cDNA, metalloproteinase1 cDNA, $\alpha 1$ (I) anda 1 (III) procollagen cDNA probes were used for in situ hybridization. First, sections were dewaxed with xylene and a descending ethanol dilution series and rinsed in phosphate-buffered saline for $1 \mathrm{~min}$. The sections were then digested with proteinase $\mathrm{K}(50 \mu \mathrm{g} / \mathrm{ml})$ for $25 \mathrm{~min}$ at $37^{\circ} \mathrm{C}$. Next, $25 \mu 1$ of the hybridization mixture (labeled cDNA probe $5 \mu 1,70 \%$ formamide $10 \mu 1,20 \times$ standard sodium citrate buffer (SSC) $4 \mu 1,50 \%$ dextran sulfate $2 \mu 1$, $50 \times$ Denhardt's solution $2 \mu 1,10 \mathrm{mg} / \mathrm{ml}$ ssDNA $1 \mu 1,1 \mathrm{~mol} / \mathrm{L}$ dithiothreitol $1 \mu 1$ ) was applied to each section under a glass coverslip and hybridized at $42^{\circ} \mathrm{C}$ for $120 \mathrm{~min}$. After the coverslips were removed in the SSC series, the sections were immersed in 1:100 horse serum for $20 \mathrm{~min}$ to remove nonspecific binding. Rabbit-anti-DIG was added at $37^{\circ} \mathrm{C}$ for $60 \mathrm{~min}$, then biotin-goat-anti-rabbit was added and the sections were incubated in a humid chamber for $20 \mathrm{~min}$ at $37^{\circ} \mathrm{C}$. After rinsing 3 times, the sections had SABC added for $30 \mathrm{~min}$ at $37^{\circ} \mathrm{C}$. The sections were rinsed again 4 times, each time for $5 \mathrm{~min}$. The color was developed using DAB$\mathrm{H}_{2} \mathrm{O}_{2}$ before the sections were stained with hematoxylin. Visualization of the in situ hybrids was enabled by DAB, resulting in dark brown spots representing the mRNA positive signals in pulmonary smooth muscle cells in the tissue sections. For pulmonary arteries, the same semi-quantitative method for assessing the signals described in the previous immunochemical analysis was used. At least 10 pulmonary arteries were assessed in each animal.

Omission of the cRNA probe on previously confirmed positive tissue sections was used as the negative controls and sections of hepatic cancer were used as the positive controls.

\section{Statistical Analysis}

The results were expressed as mean $\pm \mathrm{S}$ and the data were compared with ANOVA. The q-test was used for intergroup comparison.

\section{Results}

\section{Pressure and Hemodynamic Changes}

In the present rat model of $\mathrm{PH}, \mathrm{QP} / \mathrm{QS}$ in the shunt group and shunt $+\mathrm{L}$-arginine group was $3.32 \pm 0.90$ and $3.64 \pm 0.52$, respectively. There was no difference between these 2 values ( $>0.05)$; they were considered to be large shunts. There was a significant difference in the mean pulmonary arterial pressure among the 3 groups $(\mathrm{p}<0.01)$; the mean 
Table 1 Integral Scores of Collagen I, Collagen III, a 1 (I) anda 1 (III) Procollagen mRNA Expressions by Pulmonary Artery Smooth Muscle Cells of Rats

\begin{tabular}{lcccc}
\hline \hline Group & $\begin{array}{c}\text { Collagen I median } \\
\text { (small) }\end{array}$ & $\begin{array}{c}\text { Collagen III median } \\
(\text { small })\end{array}$ & $\begin{array}{c}\text { Proa 1 (I) mRNA median } \\
(\text { small })\end{array}$ & $\begin{array}{c}\text { Proa 1 (III) mRNA median } \\
(\text { small })\end{array}$ \\
\hline Control $(n=6)$ & $20.00 \pm 3.16$ & $23.11 \pm 2.19$ & $5.00 \pm 0.00$ & $14.44 \pm 2.29$ \\
& $(20.83 \pm 2.04)$ & $(26.52 \pm 1.69)$ & $(5.00 \pm 0.00)$ & $(14.09 \pm 1.54)$ \\
Shunt $(n=6)$ & $56.67 \pm 4.08^{*}$ & $49.91 \pm 3.34^{*}$ & $55.54 \pm 2.79 *$ & $25.46 \pm 2.53^{*}$ \\
& $\left(56.67 \pm 4.08^{*}\right)$ & $(50.93 \pm 2.27 *)$ & $\left(61.41 \pm 5.40^{*}\right)$ & $(27.35 \pm 4.04 *)$ \\
Shunt + L-arginine $(n=6)$ & $42.82 \pm 3.26 \Delta$ & $39.68 \pm 3.54 \Delta$ & $27.08 \pm 3.94 \Delta$ & $15.08 \pm 1.23 \Delta$ \\
& $(44.61 \pm 3.55 \Delta)$ & $(42.33 \pm 1.14 \Delta)$ & $(24.41 \pm 2.69 \Delta)$ & $(19.45 \pm 3.16 \Delta)$ \\
\hline
\end{tabular}

Data are mean $\pm S$.

${ }^{*} p<0.01$ vs control group; $\Delta p<0.01$ vs shunt group.

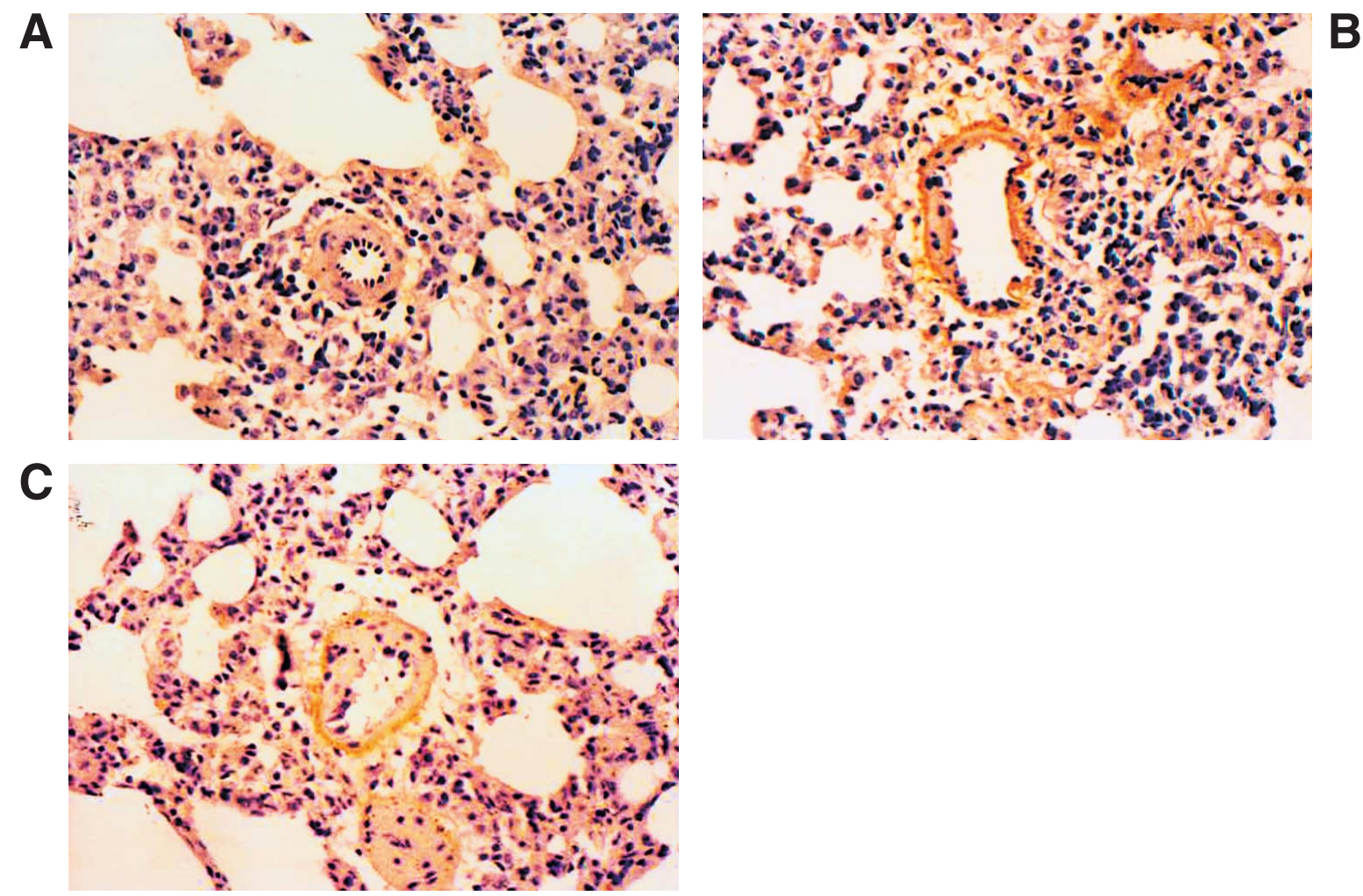

Fig 1. (A) Microphotograph of pulmonary artery with slight expression of collagen III mRNA in a control rat (DAB, $\times 400$ ). (B) Microphotograph of the pulmonary artery of a shunt rat with increased collagen III mRNA expression (DAB, $\times 400$ ). (C) Microphotograph of the pulmonary artery with decreased collagen III mRNA expression in a shunt $+\mathrm{L}$-arginine rat $(\mathrm{DAB}, \times 400)$.

pulmonary arterial pressure in the shunt group $(23.00 \pm$ $0.90 \mathrm{mmHg}$ ) was significantly increased compared with that of the control group $(15.67 \pm 1.12 \mathrm{mmHg})(\mathrm{p}<0.01)$. In the shunt $+\mathrm{L}$-arginine group, however, the mean pulmonary arterial pressure $(18.00 \pm 1.80 \mathrm{mmHg})$ was significantly lower than that of shunt group $(\mathrm{p}<0.05)$. These results show that the abdominal aorta-inferior vena cava shunt was successful.

\section{Collagen I and Collagen III Expressions by Smooth Muscle Cells of Pulmonary Arteries}

There was a significant difference in the collagen I and collagen III expression by smooth muscle cells of median and small pulmonary arteries among rats in the 3 groups $(p<0.01)$ (Table 1). The integration values of collagen I and collagen III expressions were significantly higher in rats of the shunt group than in the control group $(\mathrm{p}<0.01)$ and were significantly lower in the shunt $+\mathrm{L}$-arginine group than in the shunt group $(\mathrm{p}<0.01)$.

\section{Expressions of Procollagen I mRNA and Procollagen III} mRNA by Smooth Muscle Cells of Pulmonary Arteries

There were significant differences in procollagen I mRNA and procollagen III mRNA expressions by mediun and small pulmonary artery smooth muscle cells among the 3 groups $(\mathrm{p}<0.01)$ (Table 1; Fig 1). I and III procollagen mRNAs of pulmonary artery smooth muscle cells were obviously increased in the shunt rats as compared with normal controls $(\mathrm{p}<0.01)$. L-arginine, however, markedly reduced I and III procollagen mRNA expressions by pulmonary artery smooth muscle cells $(\mathrm{p}<0.01)$. 
Table 2 Integral Scores of Tissue Inhibitor of Metalloproteinase-1 mRNA and Metalloproteinase-1 mRNA Expressions and the Ratio of Tissue Inhibitor of Metalloproteinase-1 to Metalloproteinase-1 in Pulmonary Artery Smooth Muscle Cells of Rats

\begin{tabular}{lccc}
\hline \hline & $\begin{array}{c}\text { Tissue inhibitor of } \\
\text { metalloproteinase-1 } \\
\text { mRNA median } \\
\text { (small) }\end{array}$ & $\begin{array}{c}\text { Metalloproteinase-1 } \\
\text { mRNA median } \\
\text { (small) }\end{array}$ & $\begin{array}{c}\text { Tissue inhibitor of } \\
\text { metalloproteinase-1/ } \\
\text { metalloproteinase-1 median } \\
(\text { small })\end{array}$ \\
\hline Control $(n=6)$ & $20.19 \pm 2.04$ & $21.13 \pm 2.31$ & $0.97 \pm 0.16$ \\
& $(14.53 \pm 1.69)$ & $(14.37 \pm 2.24)$ & $(1.04 \pm 0.23)$ \\
Shunt $(n=6)$ & $61.39 \pm 4.07^{*}$ & $46.32 \pm 5.32 *$ & $1.34 \pm 0.13^{*}$ \\
& $\left(64.68 \pm 5.06^{*}\right)$ & $\left(47.92 \pm 3.23^{*}\right)$ & $\left(1.35 \pm 0.10^{*}\right)$ \\
Shunt + L-arginine $(n=6)$ & $28.74 \pm 2.35 \Delta$ & $24.87 \pm 2.02 \Delta$ & $1.16 \pm 0.10 \Delta \Delta$ \\
& $(26.06 \pm 2.42 \Delta)$ & $(23.44 \pm 2.95 \Delta)$ & $(1.13 \pm 0.17 \Delta \Delta)$ \\
\hline
\end{tabular}

Data are mean $\pm S$.

$* p<0.01$ vs control group; $\Delta p<0.01$ vs shunt group; $\Delta \Delta p<0.05$ vs shunt group.
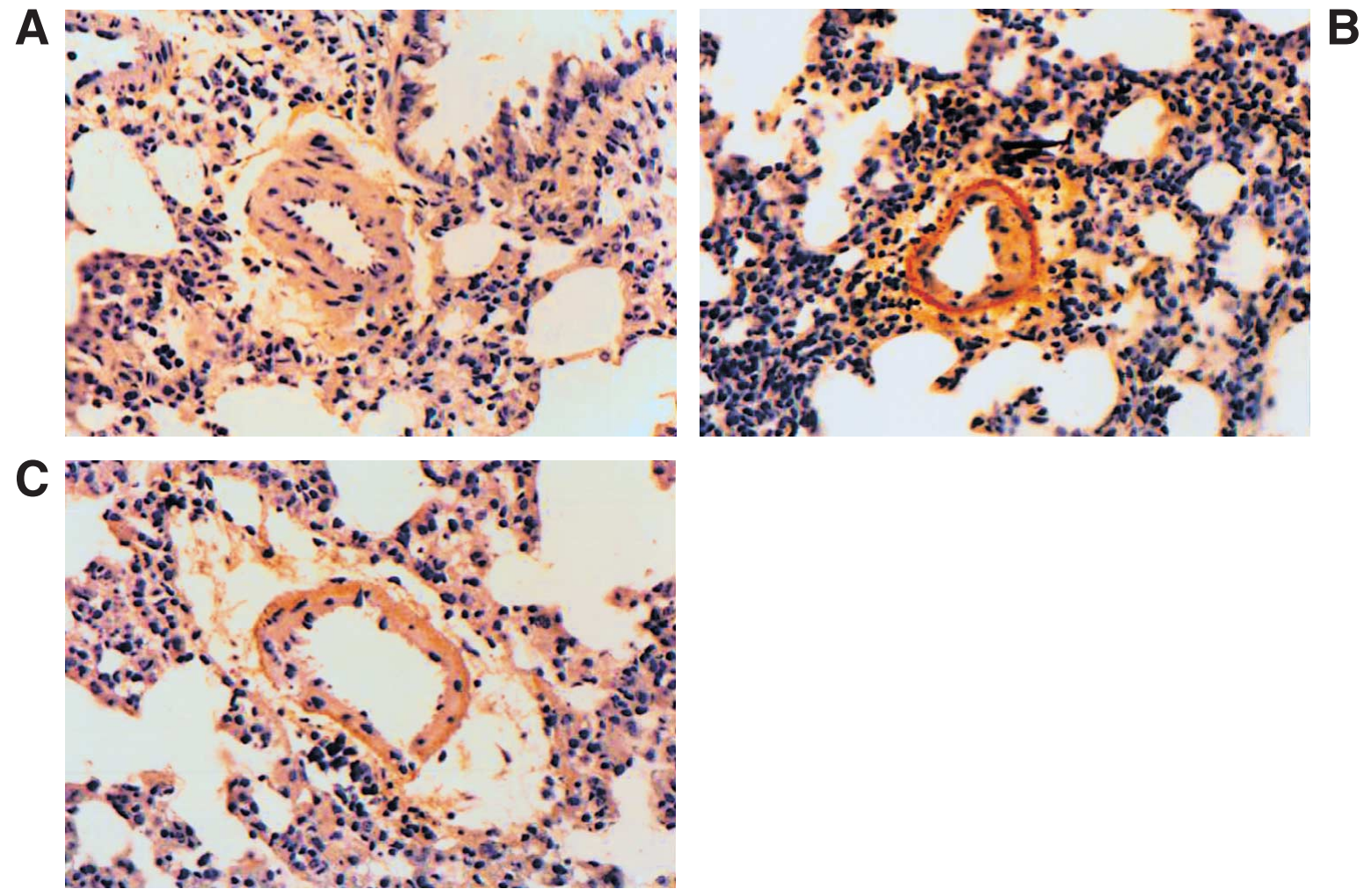

Fig 2. (A) Microphotograph of the pulmonary artery with slight expression of tissue inhibitor of metalloproteinase-1 mRNA in a control rat $(\mathrm{DAB}, \times 400)$. (B) Microphotograph of the pulmonary artery of a shunt rat with increased tissue inhibitor of metalloproteinase-1 mRNA expression (DAB, $\times 400)$. (C) Microphotograph of the pulmonary artery with decreased tissue inhibitor of metalloproteinase- 1 mRNA expression in a shunt $+\mathrm{L}$-arginine rat (DAB, $\times 400$ ).

Expressions of Pulmonary Artery Metalloproteinase-1, Tissue Inhibitor of Metalloproteinase-1 and the Ratio of Metalloproteinase-1 mRNA to Tissue Inhibitor of Metalloproteinase-1 $\mathrm{mRNA}$

Significant differences in the expressions of pulmonary artery tissue inhibitor of metalloproteinase-1 mRNA, metalloproteinase-1 mRNA and tissue inhibitor of metalloproteinase- $1 /$ metalloproteinase- 1 were noticed among the 3 groups (all $\mathrm{p}<0.05)$ (Table 2; Figs 2,3). Tissue inhibitor of metalloproteinase-1 mRNA, metalloproteinase-1 mRNA and tissue inhibitor of metalloproteinase-1/metalloproteinase-1 in the shunt group were significantly increased compared with the control group (all $\mathrm{p}<0.01$ ). However, in the shunt +L-arginine group, tissue inhibitor of metallopro- teinase-1 mRNA, metalloproteinase- 1 mRNA and tissue inhibitor of metalloproteinase-1/metalloproteinase-1 were significantly lower than in the shunt group (all $\mathrm{p}<0.05$ ).

\section{Discussion}

Nitric oxide is a potent endothelium-derived vasodilator synthesized from L-arginine by nitric oxide synthase by the vascular endothelial cells. Nitric oxide mediates pulmonary vasorelaxation, attenuates pulmonary hypertension and alleviates the development of pulmonary vascular structural remodeling6,8 Accumulation of extracellular matrix is an important component of pulmonary vascular remodeling in pulmonary hypertension and collagen protein is a major 

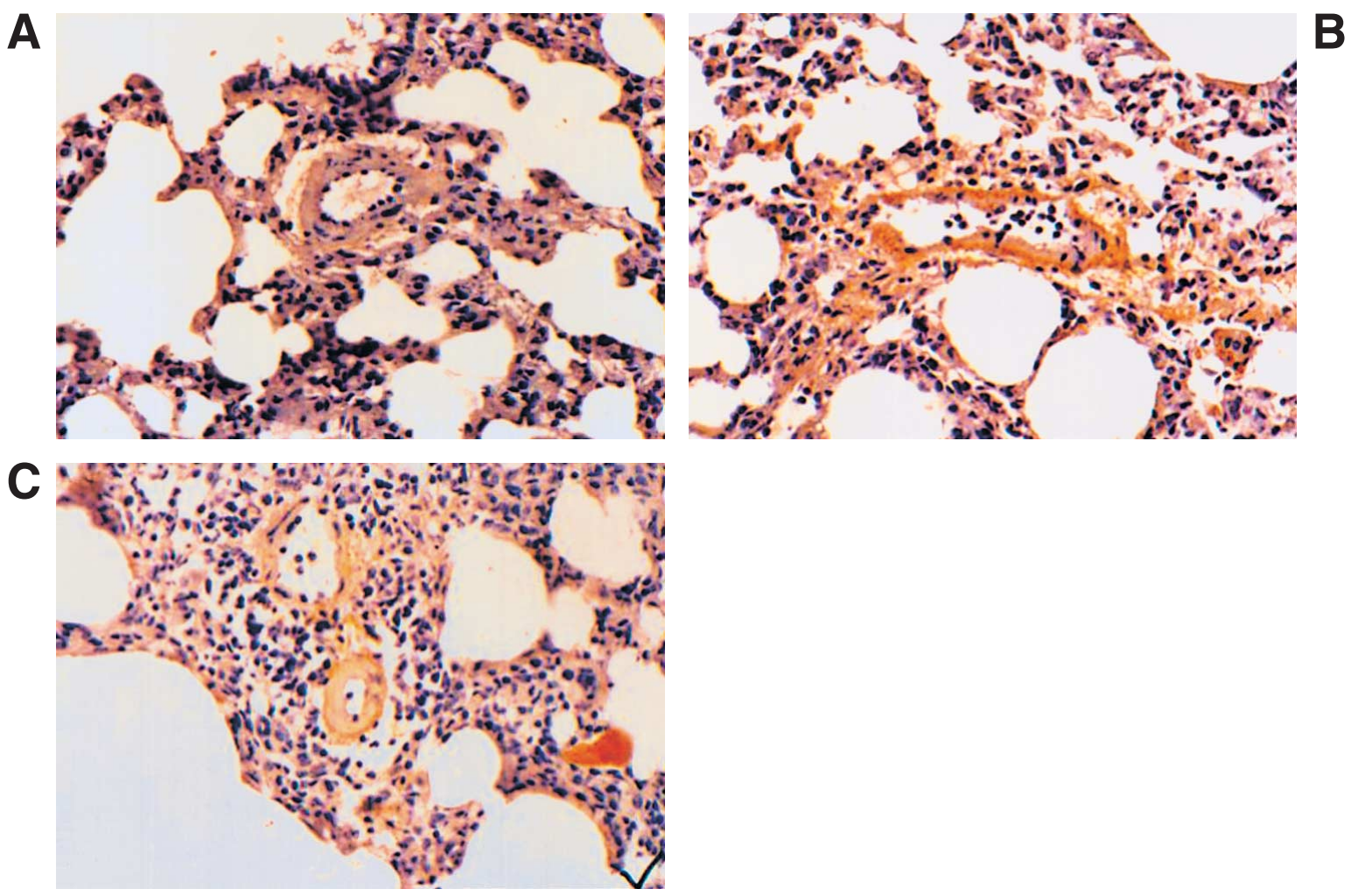

Fig 3. (A) Microphotograph of the pulmonary artery with slight expression of metalloproteinase mRNA in a control rat (DAB, $\times 400)$. (B) Microphotograph of the pulmonary artery of a shunt rat with increased metalloproteinase mRNA expression $(\mathrm{DAB}, \times 400)$. (C) Microphotograph of the pulmonary artery with decreased metalloproteinase mRNA expression in a shunt $+\mathrm{L}$-arginine rat $(\mathrm{DAB}, \times 400)$.

component of extracellular matrix. The accumulation of excess collagen in remodeled arteries may result from increased synthesis/decreased degradation of collagen. The transcription and translation of Prœ 1(I) mRNA and Pro 1 (III) mRNA are key processes in collagen synthesis, and metalloproteinase-1 and tissue inhibitor of metalloproteinase- 1 are the main molecules modulating the degradation of collagen $!^{13}$ In the process of maintaining the normal structure and function of pulmonary vessels, the expressions of collagen genes are strictly regulated and controlled to maintain a balance between the deposition and degradation of collagen in pulmonary vessels. Once this balance is destroyed, the increase in collagen synthesis or decrease in collagen degradation or both would result in extracellular matrix-collagen remodeling. So what changes would occur in pulmonary artery collagen synthesis and degradation in high pulmonary blood-induced pulmonary vascular structural remodeling? As a free radical, how would nitric oxide act on pulmonary collagen protein?

Initial studies showed that nitric oxide-donors, such as sodium nitroprusside and CAS-754, inhibited basal collagen levels in cultured vascular smooth muscle cells. ${ }^{11,12}$ The data obtained from our study also showed that collagen types I and III increased significantly in pulmonary arteries when high pulmonary blood flow existed, and L-arginine obviously decreased the basal levels of both types of collagen. Accordingly, collagen I and III proteins also markedly increased as shown in Table 1. These results indicate that nitric oxide plays an important role in the regulation of extracellular matrix-collagen, suggesting that it also regulates the breakdown of excess collagen deposited in pulmonary artery wall during PH. However, few laboratory data are available to demonstrate that L-arginine is involved in the metabolism of excess collagen deposited in the pulmonary artery wall during $\mathrm{PH}$.

Our observations suggest that the inhibition of procollagen Iand III mRNAs might be involved in the regulation of the synthesis of collagen proteins during regression of pulmonary artery remodeling by L-arginine. The pulmonary artery underwent major structural reorganization during sustained elevation of pulmonary arterial pressure. After L-arginine was used, the pulmonary artery pressure decreased. When the hypertensive stimulus was removed, the irritation and damage induced by mechanical tension transmitted across the vessel wall were reduced and the imbalance of active substances secreted by the endothelial cells in pulmonary vessels was also ameliorated. When the expressions of procollagen I and III mRNAs of pulmonary arteries were downregulated, the excess collagen proteins accumulated during $\mathrm{PH}$ decreased toward normal levels.

The results of our present study also showed marked increases in the concentrations of tissue inhibitor of metalloproteinase- $1 \mathrm{mRNA}$ and metalloproteinase- $1 \mathrm{mRNA}$ and in the tissue inhibitor of metalloproteinase-1 mRNA/metalloproteinase-1 mRNA ratio in pulmonary arteries of shunted rats, as compared with control rats, but components were decreased in the shunt $+\mathrm{L}$-arginine group as compared with shunt rats (Table 2). Coordinated control of tissue inhibitor of metalloproteinase-1 and metalloproteinase- 1 may be critical in modulating the degradation of collagen proteins under normal conditions. Metalloproteinase, tissue inhibitor of metalloproteinase, extracellular matrix and the extracellular environment have tight connections and constitute an accurate regulative network. When conditions are out of 
control, matrix remodeling occurs. Our findings showed an increase in metalloproteinase-1 expression accompanied by an increase in tissue inhibitor of metalloproteinase-1 expression of pulmonary vascular smooth muscle cells when high pulmonary blood flow-induced PH occurred. In other words, degradation of collagen protein was relatively inhibited, but after L-arginine was used, the ratio of tissue inhibitor of metalloproteinase-1 mRNA/metalloproteinase1 mRNA decreased and the expression of metalloproteinase-1 relatively increased. We speculate that another mechanism by which $\mathrm{L}$-arginine/nitric oxide modulates $\mathrm{PH}$ and alleviates extracellular matrix-collagen remodeling is probably related to promoting the breakdown of excess collagen.

Several studies have suggested that metalloproteinase-1 might be essential to smooth muscle cell migration and proliferation, which induces pulmonary vascular remodeling 14,15 In our study, an increase in metalloproteinase-1 expression was observed during both the development and the reversal of extracellular matrix-collagen remodeling, a result that was consistent with the study of Vieillard-Baron et al ${ }^{16}$ They reported that at the beginning of pulmonary vascular remodeling, the activity of metalloproteinase-1 was higher than that of tissue inhibitor of metalloproteinase-1, but later, the activity of tissue inhibitor of metalloproteinase-1 kept increasing, whereas the activity of metalloproteinase-1 was relatively inhibited. However, in the recovery phases of remodeling, the activity of metalloproteinase-1 appeared to increase once more. Activation of metalloproteinase- 1 may initiate $\mathrm{PH}$, and it may also play a crucial role in protecting against the development of PH. In the whole course of pulmonary vascular remodeling, the determinant of collagen degradation was neither the expression nor the activity of metalloproteinase- 1 , but the balance between metalloproteinase-1 and tissue inhibitor of metalloproteinase-1.

Our study explored the modulating effect of L-arginine on $\mathrm{PH}$ induced by a left-to-right shunt and its possible mechanism from the viewpoint of collagen metabolism, which is important for increasing our understanding of the effect and mechanism by which it attenuates high pulmonary blood flow-induced pulmonary vascular structural remodeling and is implicated in the treatment of the $\mathrm{PH}$ with congenital heart diseases.

\section{Acknowledgments}

This work was supported by Bio-X Center Foundation of Peking Uni- versity, Beijing Natural Science Foundation (7033047), the Major Basic Research Program of China (G2000056905) and the State Foundation for Excellent Young Scholars (30425010).

\section{References}

1. Dzau VJ, Gibbons GH. Vascular remodeling: Mechanisms and implication. J Cardiovasc Pharmacol 1993; 21(Suppl): S1-S5.

2. Gibbons GH, Dzau VJ. The emerging concept of vascular remodeling. N Engl J Med 1994; 330: 1431 - 1438 .

3. Laurent GJ, Bishop JE, Gray A, Peacock A, Harrison NK, Winrove $\mathrm{CP}$, et al. Deposition of arterial collagens in pulmonary hypertension: Putative role for growth factors derived from the circulation. In: Widimsky J, Herget J, editors. Pulmonary blood vessels in lung disease. Basel: Karger; 1990; 54-62.

4. Bishop JE, Guerreiro D, Laurent GJ. Changes in the composition and metabolism of arterial collagens during the development of pulmonary hypertension in rabbits. Am Rev Respir Dis 1990; 141: 450455.

5. Tozzi CA, Christiansen DL, Poiani GJ, Riley DJ. Excess collagen in hypertensive pulmonary arteries decreases vascular distensibility. Am J Respir Crit Care Med 1994; 149: 1317-1326.

6. Qi JG, Du JB, Li J, Wei B, Tang CS. The effect of L-arginine on high pulmonary blood flow-induced pulmonary hypertension. J Appl Clin Pediatr 2001; 16: 263-265.

7. Vanhoutte PM. Endothelial control of vascular function: From health to coronary disease. Circ J 2003; 67: 572-575.

8. Furchgott RF, Zawadzki JV, Mitani Y, Maruyama K, Sakurai M. Prolonged administration of L-arginine ameliorates chronic pulmonary hypertension and pulmonary vascular remodeling in rats. Circulation 1997; 96: 689-697.

9. Garcia R, Diebold S. Simple, rapid, and effective method of producing aortocaval shunts in the rat. Cardiovasc Res 1990; 24: 430-432.

10. Furchgott RF, Zawadzki JV. The obligatory role of endothelial cells in the relaxation of arterial smooth muscle by acetylcholine. Nature 1980; 288: $373-376$.

11. Kolpakov V, Gordon D, Kulik TJ. Nitric oxide-generating compounds inhibit total protein and collagen synthesis in cultured vascular smooth muscle cells. Circ Res 1995; 76: 305-309.

12. Rizvi MA, Myers PR. Nitric oxide modulates basal and endothelininduced coronary artery vascular smooth muscle cell proliferation and collagen levels. J Mol Cell Cardiol 1997; 29: 1779-1789.

13. Thakker-Varia S, Tozzi C, Poiani GJ, Babiarz JP, Tatem L, Wilson FJ, et al. Expression of matrix-degrading enzymes in pulmonary vascular remodeling in the rat. Am J Physiol 1998; 275: L398-L406.

14. Bendeck MP, Zempo N, Clowes AW, Galardy RE, Reidy MA. Smooth muscle cell migration and matrix metalloproteinase expression after arterial injury in the rat. Circ Res 1994; 75: 539-545.

15. Zempo N, Koyama N, Kenagy RD, Lea HJ, Clowes AW. Regulation of vascular smooth muscle migration and proliferation in vitro and in injured rat arteries by a synthetic matrix metalloproteinase inhibitor. Arterioscler Thromb Vasc Biol 1996; 16: 28-33.

16. Vieillard-Baron A, Frisdal E, Eddahibi S, Deprez I, Baker AH, Newby AC, et al. Inhibition of matrix metalloproteinases by lung tissue inhibitor of metalloproteinase-1 gene transfer or doxycycline aggravates pulmonary hypertension in rats. Circ Res 2000; 87: 418 425. 